\title{
Morphometric Study of Dorsalis Pedis Artery and Variation in its Branching Pattern: A Cadaveric Study
}

Chandni Gupta ${ }^{1}$, Rakesh Kumar ${ }^{1}$, Vikram Palimar ${ }^{2}$, Sneha Guruprasad Kalthur ${ }^{1}$

${ }^{1}$ Department of Anatomy, Kasturba Medical College, Manipal University, Manipal India, 576104

${ }^{2}$ Department of Forensic Medicine, Kasturba Medical College, Manipal University, Manipal India, 576104

\begin{abstract}
Introduction: Dorsalis pedis artery (DPA) is the chief artery that supplies the dorsum of the foot. Palpation of DPA at the dorsum of the foot is important in case of atherosclerotic disease. A sound knowledge of DPA like its branching pattern is essential for the ankle surgeries as well as its presence or absence in case of peripheral vascular disease. Material and methods: 30 Lower limbs of unknown age and sex were dissected in the department of Anatomy, Kasturba Medical College, Manipal. The skin and fascia were removed.The measurement of Dorsalis pedis artery till its termination, Length from medial malleolus, Length from lateral malleolus and branching pattern of Dorsalis pedis artery was studied. Results: In this study, the average length of dorsalis pedis artery was found $7.8 \mathrm{~cm}$, average length from medial malleolus was $3.9 \mathrm{~cm}$ and average length from lateral malleolus was $4.5 \mathrm{~cm}$. The normal branching pattern of medial tarsal artery was noticed in $53 \%$ and lateral tarsal artery in $63 \%$ cases. The arcuate artery was absent in $3 \%$ of cases. Conclusion: The knowledge of the variation of DPA is helpful during various foot surgeries. Knowledge of the variation will be useful in deciding whether the absence of the pulse in DPA is due to thrombosis of the vessel or its abnormal course or absence. DPA does not always lie at mid -malleolar point.
\end{abstract}

KEYWORDS: Dorsalis pedis artery, length, medial malleolus, lateral malleolus, branching pattern.

\section{INTRODUCTION}

The dorsalis pedis artery is a main blood vessel of the lower limb that carries oxygenated blood to the dorsal surface of the foot. It arises out at the anterior aspect of the ankle joint. It is a continuation of the anterior tibial artery at the mid malleolar point. It terminates at the proximal part of the $1^{\text {st }}$ metatarsal space where it divides into two branches, the $1^{\text {st }}$ dorsal metatarsal artery and deep plantar artery which ends by forming the plantar arterial arch. Its other branches are medial and lateral tarsal arteries. ${ }^{1}$

The dorsalis pedis artery is mainly used to feel the pulse in cases of peripheral vascular diseases. It can be palpated lateral to the extensor hallucis longus tendon (or medial to the extensor digitorum longus tendon) on the dorsal surface of the foot distal to the dorsal most prominence of the navicular bone which serves as a reliable landmark for pulsation. Sometimes the pulse can be absent unilaterally or bilaterally in the patient having peripheral vascular disease.

Corresponding author:

Dr. Chandni Gupta

Associate Professor

Department of Anatomy,

KMC Manipal,India 576104

E-mail:chandnipalimar@gmail.com
Nowadays, due to stress and depression, people are more prone to Diabetes mellitus and high blood pressure. In diabetic neuropathy there are more chances of foot infection and ischemia, in such cases foot amputation is required. DPA bypass plays a major role in these cases for salvaging the ischemic limb. The dorsalis pedis artery (DPA) with its main branches is preferentially used as a recipient vessel. The myocutaneous dorsalis pedis arterialised flap can be safely used as an island flap, to cover the ankle or heel and as a free flap for palm defects. ${ }^{2}$

Therefore, thorough information about the vessels of the foot and its variations is required in such circumstances. So, the aim of the study is to observe the origin, course and branching pattern of dorsalis pedis artery and its variations and to measure the length of dorsalis pedis artery and its distance from the medial and lateral malleolus in the intermalleolar line.

\section{MATERIALS AND METHODS}

30 lower limbs of unknown sex and age were dissected carefully. Skin, superficial fascia was reflected and extensor retinaculum was cut to look for dorsalis pedis artery, which was lying between the tendons of the extensor hallucis longus and extensor digitorum longus. Then the artery was traced from its origin to termination and painted for clear vision. Measurements on dorsalis pedis artery were done like: (figure 1) 
1. Length of the Dorsalis pedis artery- it was measured from an intermalleolar line to its dipping in $1^{\text {st }}$ intermetatarsal space,

2. Distance of the artery from the medial malleolus

3. Distance of the artery from the lateral malleolus

In the cases of variation in origin and branching pattern photographs were taken. Results were analyzed using SPSS- software.

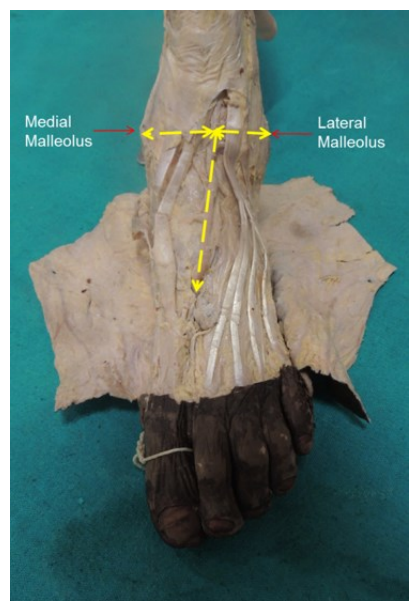

Figure 1. Showing measurements done on dorsalis pedis artery.

\section{RESULTS}

Measurements done on dorsalis pedis artery are shown in table I.

Table I. Showing mean of all the measurements done on DPA

\begin{tabular}{lc}
\hline \multicolumn{1}{c}{ Parameters } & Mean length (cms) \\
\hline Length of dorsalis pedis artery & 7.8 \\
Distance from medial mallelous & 3.9 \\
Distance from lateral mallelous & 6.0 \\
\hline
\end{tabular}

A distance of dorsalis pedis artery from the two malleoli showed that dorsalis pedis artery does not always lies at the midmalleolar point. It lies close to medial malleolus as compared to lateral malleolus.

Variation in the branching pattern is shown in table II. (Figure 2 and 3).

In one case there was a lateral deviation of the dorsalis pedis artery. It deviates towards the lateral side on dorsum of foot and then comes to $1^{\text {st }}$ intermetatarsal space and pierces it and joins the plantar arterial arch. (Figure 4)

In one case in our study dorsalis pedis artery was absent.

Table II. Showing comparison of variation in origin, course and absence of dorsalis pedis artery in our study with other authors

\begin{tabular}{|c|c|c|}
\hline BRANCHES & $\begin{array}{c}\text { BRANCHING } \\
\text { PATTERN }\end{array}$ & $\begin{array}{l}\text { PERCENTAGE } \\
\%\end{array}$ \\
\hline $\begin{array}{l}\text { Lateral Tarsal } \\
\text { Artery (LTA) }\end{array}$ & $\begin{array}{l}\text { Normal } \\
\text { Two LTA } \\
\text { Three LTA }\end{array}$ & $\begin{array}{c}66.3 \\
30 \\
3.3\end{array}$ \\
\hline $\begin{array}{l}\text { Medial Tarsal } \\
\text { Artery } \\
\text { (MTA) }\end{array}$ & $\begin{array}{l}\text { Normal } \\
\text { One MTA }\end{array}$ & $\begin{array}{c}59.9 \\
40\end{array}$ \\
\hline $\begin{array}{l}1^{\text {st }} \text { Dorsal } \\
\text { Metatarsal Artery }\end{array}$ & Normal & 100 \\
\hline Arcuate artery (AA) & $\begin{array}{l}\text { Normal } \\
\text { Absent }\end{array}$ & $\begin{array}{l}97 \\
03\end{array}$ \\
\hline
\end{tabular}
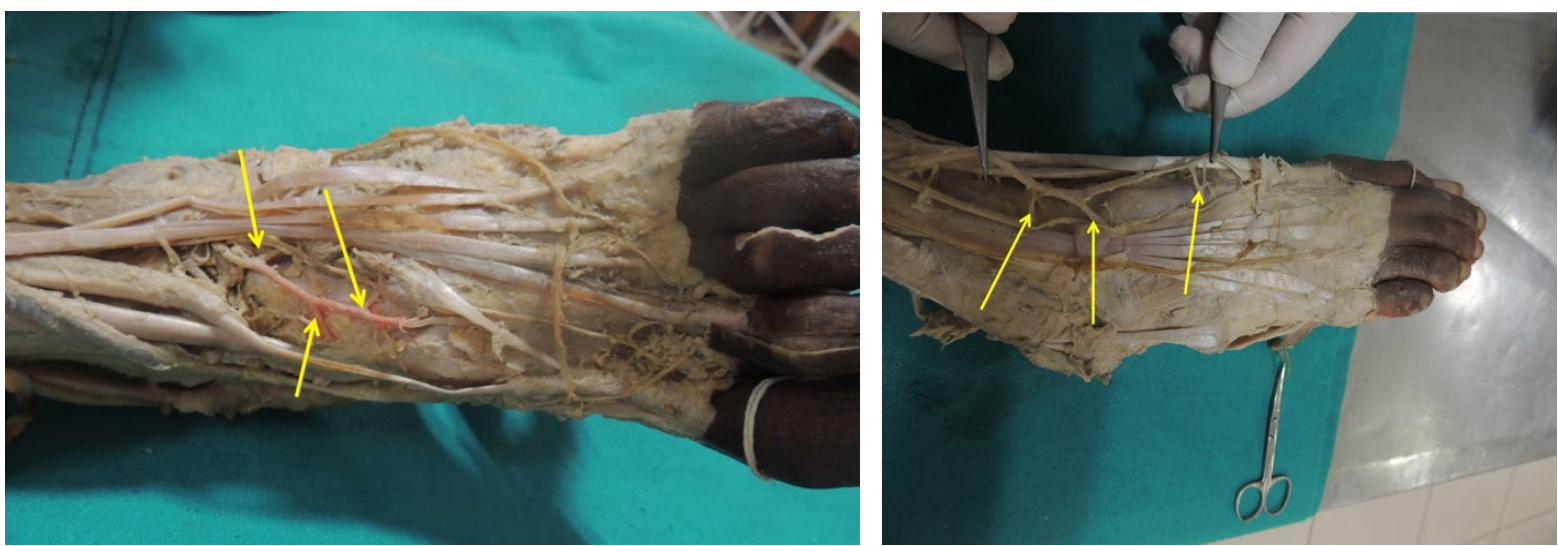

Figure 2. Showing two and three branches of lateral tarsal artery (LTA) and one branch of medial tarsal artery (MTA) 
Absent Arcuate Artery

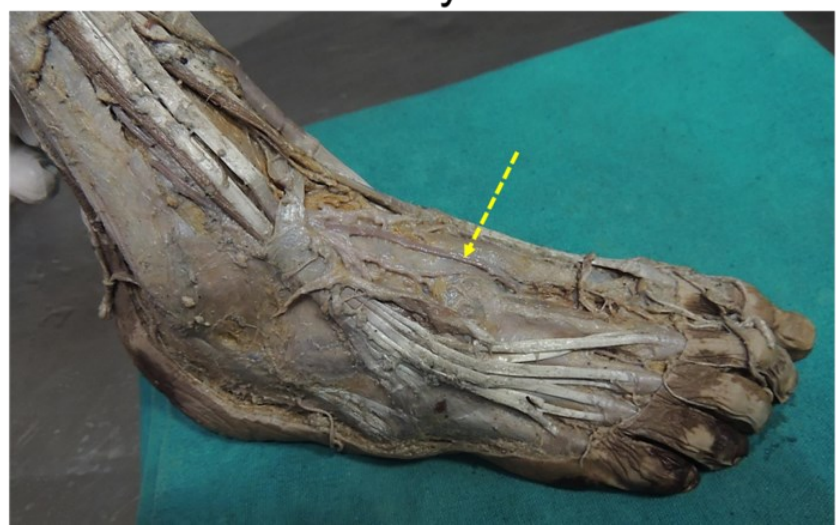

Figure 3. Showing absent arcuate artery

\section{DISCUSSION}

Variations in the blood vessels and their abnormal course can be attributed to their development. Small blood vessels (which are derived from the blood islands in the $3^{\text {rd }}$ or $4^{\text {th }}$ week of development) unite and form a continuous network, from which buds grow out later. These buds canalize and form new vessels. Depending on the functional dominance, some vessels degenerate and others diverge in the mode of origin and course of the principal vessel. ${ }^{3}$

Palpation of the Dorsalis pedis artery is important, especially in arterial diseases. The Dorsalis pedis artery pulse can be felt on the dorsum of the foot, where it passes over the navicular and the cuneiform bones lateral to the extensor hallucis tendon. The pulse may also be felt at the proximal end of $1^{\text {st }}$ dorsal interosseous space. ${ }^{2}$ Sometimes dorsalis pedis artery can be absent as we found in 1 case $(3 \%)$ in the present study. Rajeshwari MS et al found that in $9.52 \%$ of cases and Yamada et al reported absence of dorsalis pedis artery in $6.7 \%$ of cases. Huber. JF found that in $14 \%$ of cases the artery was either absent or too small to palpate. ${ }^{1,4}$ and 5 This should be clear in mind while physical examination of a person in cases of peripheral arterial diseases, thrombosis, thrombo-angitis obliterans, acute embolism in which pulse distal to the occlusion site is lost. ${ }^{2}$

Huber. JF found that in $9 \%$ of cases, the artery deviated from its normal course, either laterally or medially. ${ }^{4}$ We found in our study that in $3 \%$ of cases dorsalis pedis artery deviates to the lateral side of the foot from its normal course.

Comparison in the variation of origin, course and absence of dorsalis pedis artery in our study and with other authors is shown in Table III.

\section{Lateral deviation of Dorsalis Pedis Artery}

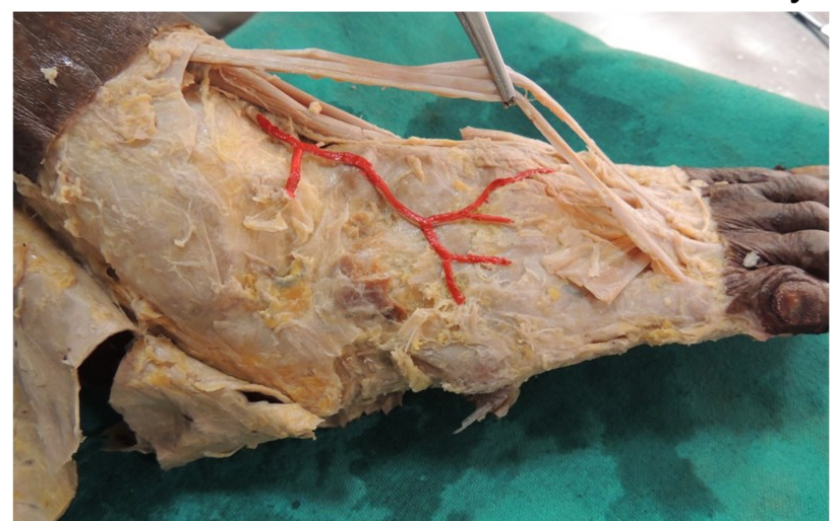

Figure 4. Showing lateral deviation of dorsalis pedis artery.

Table III. Showing branching pattern of DPA

\begin{tabular}{lll}
\hline PARAMETERS & VIJAYALAKSHMI S. & $\begin{array}{l}\text { PRESENT } \\
\text { STUDY }\end{array}$ \\
\hline NORMAL DPA & $56 \%$ & $91 \%$ \\
ABSENCE AA & $6 \%$ & $3 \%$ \\
Lat. Deviation & $2 \%$ & $3 \%$ \\
DPA Absent & $2 \%$ & $3 \%$ \\
\hline
\end{tabular}

Vijayalakshmi $S$ et al found in 8 cases that the dorsalis pedis artery has a short straight course and later divided into medial and lateral branches. The medial branch continued as the first dorsal metatarsal artery and joined the plantar arch. The lateral branch coursed obliquely towards the head of the other metatarsal bones and gave off the second, third and fourth metatarsal arteries which coursed in the inter-metatarsal spaces. They named the medial and lateral branches as: dorsalis arteria medialis and dorsalis arteria lateralis. ${ }^{2}$ We did not find any such cases in the present study.

Comparison of the variation in the branching pattern of dorsalis pedis artery in our study and with other authors is shown in table IV.

Table IV. Showing comparison of variation in branching pattern of dorsalis pedis artery in our study with other authors

\begin{tabular}{lll}
\hline Parameters & M.S.Rajeshwari & Present study \\
\hline $\begin{array}{l}\text { 3 Lateral tarsal } \\
\text { artery }\end{array}$ & $2.38 \%$ & $3.3 \%$ \\
$\begin{array}{l}2 \text { Lateral tarsal } \\
\text { artery }\end{array}$ & $14.29 \%$ & $30 \%$ \\
$\begin{array}{l}\text { Arcuate arery } \\
\text { absence\} }\end{array}$ & $16.67 \%$ & $3 \%$ \\
\hline
\end{tabular}


We also found that the arcuate artery was absent in $3 \%$ of cases. Yamada et al in his study found $33 \%$ of absence of arcuate artery, Dilandro et al reported $83.3 \%$ of the absent arcuate artery suggesting that the arcuate artery is not the primary blood supply to dorsal metatarsal artery as is commonly described. They also found that the lateral tarsal artery provided $2 \mathrm{nd}$, 3rd and $4^{\text {th }}$ dorsal metatarsal artery more frequently in $47.2 \%$ than the arcuate artery. Rajeshwari MS et al found the same branching pattern in $2.38 \%$ of cases where three lateral tarsal arteries called as the proximal, intermediate and distal lateral tarsal artery continued over the metatarsals as the 2nd, 3rd and 4th dorsal metatarsal artery. They also found that in the remaining $14.29 \%$ of cases the lateral tarsal arteries were two in number, the proximal and distal providing the dorsal metatarsal arteries. The caliber of 3rd and 4th dorsal metatarsal arteries was very small. Rajeshwari MS et al also found that in $2.38 \%$ of cases the arcuate artery was replaced by a U- shaped loop formed by the union of proximal and distal lateral tarsal artery, which provided the second and third dorsal metatarsal arteries and the fourth dorsal metatarsal artery was completely absent. Yamada et al also reported in their study the presence of proximal and distal lateral tarsal artery, which gave the dorsal metatarsal arteries. ${ }^{1,5}$ and 6

Vengadesan. $B$ found that in $90 \%$ of cases the dorsalis pedis artery has normal course and branching pattern which was similar to our study. They also found in one case lateral deviation of the dorsalis pedis artery as we found in our study. ${ }^{7}$

An abnormality of the normal anatomic pattern of origin, branching and anastomosing pattern are therefore of key significance in surgical operative procedures. Earlier validation by angiography for any anomalies will avoid unnecessary surgical hazards. ${ }^{2}$

The knowledge of the variation of the Dorsalis pedis artery is helpful during various foot surgeries. The surgeons should note that dorsalis pedis artery does not lie on the mid malleolar point. It lies close to medial malleolus as compared to the lateral malleolus.

It also plays a major role in microvascular surgeries of the foot during replantation, reconstruction and repair due to its specific anatomical position and major supply to the foot. ${ }^{2}$

\section{REFERENCES}

1. Rajeshwari MS, Roshankumar BN, Vijayakumar. An Anatomical Study on Dorsalis pedis artery. Int J Anat Res, 2013; 02:88-92.

2. Vijayalakshmi S, Raghunath G, Shenoy V. Anatomical study of Dorsalis pedis artery and its clinical correlations. Journal of Clinical and Diagnostic Research. 2011; 5(2):287-290.

3. Sadler TW. In Langman's Medical Embryology, 5th edition, Willam and Wilkins, 1985: 68- 69.

4. Huber. JF. The arterial network supplying the dorsum of foot. Anatomical Records. 1941; 80: 373.

5. Yamada T, Glovicki.P, Bower.TC. Variations of the arterial anatomy of foot. American Journal of Surgery. 1993; 166 (2): $130-135$.

6. Dilandro.AC, Lilja.EC, Lepore.FL. The prevalence of arcuate artery and a cadaveric study of 72 feet. Journal of American Podiatriac Medical Association. 2001; 91 (6): 300 - 305.

7. Vengadesan B, Pushpalatha K. An Anatomical Study on Dorsalis Pedis Artery. International Journal of Science and Research. 2017;6(2):147149. 